\title{
Rod-shape porous carbon derived from aniline modified lignin for symmetric supercapacitors
}

4 Keliang Wang ${ }^{\mathrm{a}}$, Yuhe $\mathrm{Cao}^{\mathrm{a}}$, Xiaomin Wang ${ }^{\mathrm{a}}$, Maria Castro ${ }^{\mathrm{c}}$, Bing Luo ${ }^{\mathrm{d}}$, Zhengrong Gu ${ }^{\mathrm{a}, *}$, Jun

\section{Abstract:} capacitor.

\author{
Liu $^{\text {e }}$, James D Hoefelmeyer ${ }^{\mathrm{f}}$, Qihua Fan ${ }^{\mathrm{b}, *}$
}

a Agricultural and Biosystems Engineering Department, South Dakota State University, Brookings, SD 57007, United States

b Electrical Engineering and Computer Science Department, South Dakota State University, Brookings, SD 57007, United States

c Department of Chemistry, University of Iowa, Iowa City, IA, 52242, United States

$d$ Characterization Facility of the University of Minnesota, Minneapolis, MN 55455, United States

e Energy Processes and Materials Division, Pacific Northwest National Laboratory, Richland, WA 99354, United States

f Department of Chemistry, University of South Dakota, Vermillion, SD 57069, United States

Rod-shape porous carbon was prepared from aniline modified lignin via $\mathrm{KOH}$ activation and used as electrode materials for supercapacitors. The specific surface area, pore size and shape could be modulated by the carbonization temperature, which significantly affected the electrochemical performance. Unique rod-shape carbon with massive pores and a high BET surface area of $2265 \mathrm{~m}^{2} \mathrm{~g}^{-1}$ were obtained at $700{ }^{\circ} \mathrm{C}$ in contrast to irregular morphology created at other carbonization temperatures. In $6 \mathrm{~mol} \mathrm{~L}^{-1} \mathrm{KOH}$ electrolyte, a specific capacitance of $336 \mathrm{~F}$ $\mathrm{g}^{-1}$, small resistance of $0.9 \Omega$ and stable charge/discharge at current density of $1 \mathrm{~A} \mathrm{~g}^{-1}$ after 1,000 cycles were achieved using rod-shape porous carbon as electrodes in an electrical double layer

\footnotetext{
${ }^{\text {a }}$ Z R. Gu Tel./fax: + 1605688 5372. Email address: zhengrong.gu@sdstate.edu (Z R. Gu)

${ }^{\text {b }}$ Q H. Fan Tel./fax: + 1605 688-5910. Email address: qihua.fan@sdstate.edu (Q H. Fan)
} 
24 Keywords: rod-shape porous carbon, lignin, activation, supercapacitor

\section{1. Introduction}

26 Supercapacitors, also known as electrochemical capacitors have received considerable attention

27 because of their high power density, fast charge/discharge capability and long cycle life [1-3].

28 Supercapacitors can be classified into two major categories based on the energy storage

29 mechanism: electrical double layer capacitor (EDLC) and pseudocapacitor [4]. Energy stored in

30 an EDLC is proportional to the electrostatic charge accumulated at the electrode/electrolyte

31 interface. Therefore, the specific capacitance depends on the electrode surface area accessible to

32 the electrolyte. On the other hand, pseudocapacitors store energy via the Faradaic reactions that

33 occurr between the electrode materials and electrolyte. Pseudocapacitors usually use metal

34 oxides/hydroxides (e.g. $\mathrm{MnO}_{2}, \mathrm{NiO}, \mathrm{Ni}(\mathrm{OH})_{2}, \mathrm{Co}_{3} \mathrm{O}_{4}$ ) electrodes and possess higher specific

35 capacitance than EDLCs that use carbon as electrode materials [5-9]. Pseudocapacitors are

36 expected to find broader applications if their cycle stability can be improved, electrical

37 conductivity can be increased, and the material cost can be reduced $[10,11]$.

38 Carbon-based materials are the primary electrode materials for EDLC. Porous carbon, such as 39 activated carbon (AC), mesoporous carbon and graphene [12-14] have been commonly used in 40 EDLC. EDLC electrode materials should possess the following characteristics: i) high specific 41 surface area that provides sufficient accessible surface to the electrolyte; ii) proper pore size that 42 allows the electrolyte ions to transfer smoothly with short diffusion pathways; iii) excellent 43 electrical conductivity to minimize resistive loss during charge/discharge; iv) sustainable and 44 wide availability with low cost. The preparation of mesoporous carbon usually involves complex 45 synthetic procedures in most cases, while graphene suffers from high cost although it could be 46 obtained in labs after a series of harsh chemical treatments. Alternatively, activated carbon 
47 derived from abundant, renewable biomass feedstock can be produced sustainably at low cost 48 [15]. So far, carbon materials derived from biomass such as rice husk, coffee grounds, grape seed, 49 cornstalk, banana peel [16-20], have been explored as electrode materials in EDLC and 50 promising electrochemical performance has been demonstrated.

51 Recent research showed that introducing nitrogen into activated carbon could induce additional 52 pseudo-capacitance via reversible redox reactions and improve the wettability between the 53 electrodes and electrolytes [21]. As a result, the capacitance performance of EDLC was greatly 54 promoted. Therefore, biomass derived carbon materials with nitrogen may be promising 55 electrode materials for EDLC. Since biochar typically contains low nitrogen content, we 56 hypothesize that combination of nitrogen rich compounds with biomass will lead to biochar with 57 high nitrogen content. Furthermore, there may be opportunities to tune the physicochemical 58 properties of the nitrogen rich biochar, such as morphology, surface area, and conductance. 59 Regarding the source of nitrogen, aniline appears a promising candidate because it is easy to 60 polymerize, and the polymer can be grown into different shapes such as wires, tubes and spheres $61[22-24]$ by controlling the synthetic conditions.

62 Herein, we present aniline modified lignin as the raw materials to prepare rod-shape porous 63 carbon as EDLC electrode materials. It is shown that the chemical activation plays a key role in 64 achieving large specific surface area, uniform pore size distribution and good conductivity, 65 which lead to excellent electrochemical performance.

\section{2. Experimental}

\subsection{Preparation of activated carbon}

68 Solvent lignin $(3 \mathrm{~g})$, aniline $(1.5 \mathrm{ml})$ and $30 \mathrm{ml}$ ethanol were added into a flask with $30 \mathrm{ml}$ 69 ethanol, followed by stirring at $80^{\circ} \mathrm{C}$ until the ethanol was evaporated. Then the mixture was 
70 heated at $400{ }^{\circ} \mathrm{C}$ for one hour with a heating rate of $10^{\circ} \mathrm{C} \min ^{-1}$ for $1 \mathrm{~h}$ in a muffle furnace $(1100$

71 box furnace, Lindberg/Blue M, Thermo Scientific Inc.) under the protection of nitrogen (flow

72 rate was $96 \mathrm{ml} \mathrm{min}^{-1}$ ). After the precarbonized material was cooled to room temperature, it was 73 mixed with potassium hydroxide $(\mathrm{KOH}$, Fisher Scientific Inc.) in a mass ratio of 1:3, in a steel 74 crucible also containing $30 \mathrm{~mL}$ deionized water. The crucible was placed in an oven and dried at $75110^{\circ} \mathrm{C}$ for $24 \mathrm{~h}$. Then, the crucible was transferred into a muffle and activated at $600 \sim 900{ }^{\circ} \mathrm{C}$ for $761 \mathrm{~h}$ with a heating rate of $10^{\circ} \mathrm{C} \min ^{-1}$ under $\mathrm{N}_{2}$ protection (flow rate was $96 \mathrm{ml} \mathrm{min}^{-1}$ ). 77 Afterwards, the carbonized solids were washed with $30 \mathrm{~mL} 0.1 \mathrm{~mol} \mathrm{~L}^{-1} \mathrm{HCl}$ (Fisher Scientific 78 Inc.) at $110^{\circ} \mathrm{C}$ for $1 \mathrm{~h}$ in a $60 \mathrm{~mL}$ polytetrafluoroethylene (PTFE) autoclave to remove the 79 residual $\mathrm{KOH}$ and impurities. Finally, the carbon solid was washed several times with deionized 80 water until the $\mathrm{pH}$ stabilized at 7 . The material was then dried at $105^{\circ} \mathrm{C}$ overnight in an oven. 81 The carbonized samples were denoted as PL-600, PL-700, PL-800 and PL-900, corresponding to 82 the activation temperature of $600{ }^{\circ} \mathrm{C}, 700{ }^{\circ} \mathrm{C}, 800^{\circ} \mathrm{C}$, and $900{ }^{\circ} \mathrm{C}$, respectively. In addition, the 83 carbon material derived from lignin (L) with the same method at $700{ }^{\circ} \mathrm{C}$ but without $\mathrm{KOH}$ was 84 used as control sample.

\subsection{Preparation of electrodes}

86 Electrodes were prepared by mixing the activated carbon PL-600, PL-700, PL-800, PL-900 and $87 \mathrm{~L}(80 w t \%)$ with acetylene black $(10 w t \%)$ and PTFE $(10 w t \%)$, and then pressing onto a surface 88 area of $1 \mathrm{~cm}^{2}$ nickel foam (EQ-bcnf-16m, MTI Corp.). The electrodes were dried at $60{ }^{\circ} \mathrm{C}$ 89 overnight in an oven. Afterwards, a sandwich structure was formed by placing two pieces of 90 microporous PP separator celgard-3501 between two electrodes in a coin cell 2032 type system. 91 Finally, the cell was pressed under a pressure of $1,000 \mathrm{~kg} \mathrm{~cm}^{-2}$ to finish the assembly. 


\section{$92 \quad 2.3$ Physical characterization}

93 X-ray photoelectron spectroscopy (XPS) was performed on an SSX-100 system (Surface Science

94 Laboratories, Inc.) equipped with a monochromated $\mathrm{Al} K_{\alpha} \mathrm{X}$-ray source. For high resolution

95 data, the lowest binding-energy $\mathrm{C} 1 \mathrm{~s}$ peak was set at $285.0 \mathrm{eV}$ and used as the reference for all of 96 the other elements. Raman spectra were obtained on a Horiba LABRam confocal Raman 97 microscopean with excitation wavelength of $532 \mathrm{~nm}$ from a diode pumped solidstate laser. 98 Isothermal adsorption analyses with $\mathrm{N}_{2}$ were carried out at $77 \mathrm{~K}$ (liquid nitrogen bath), using 99 Tristar 3000 Micropore analyzer. The specific surface area was determined by the Brunauer100 Emmett-Teller (BET) method and the pore size distribution was calculated according to the 101 density functional theory (DFT) method [25] using NLDFT analysis for carbon with slit pore 102 model (Micromeritics Inc.). Elemental analysis was conducted using Perkin Elmer 2400 II for C, $103 \mathrm{H}$ and $\mathrm{N}$ analysis and LECO Tru Spec Micro was used to analyze O with oxygen module. A 104 transmission electron microscope (TEM) (JEM-2100 LaB6, JEOL) equipped with energy105 dispersive X-ray spectroscopy (EDX) was used to study the morphology, microstructure, and 106 elemental mapping of the materials at an acceleration voltage of $80 \mathrm{kV}$. Additionally, a Technai 107 Spirit G2 Twin (FEI Company) TEM operating at $120 \mathrm{kV}$ was used to acquire some of the 108 micrographs.

1092.4 Electrochemical characterization:

110 Cyclic voltammetry (CV) and electrochemical impedance spectroscopy tests were measured on 111 an electrochemical work station (SP-150, BioLogical, France) in $6 \mathrm{~mol} \mathrm{~L}^{-1} \mathrm{KOH}$ electrolyte. The 112 galvanostatic charge/discharge curves were obtained from a battery test system (BTS series, 113 NEWARE, China). 


\section{Results and discussion}

115 TEM images of PL-700 with different magnifications are shown in Fig. 1. In contrast to the chunk shape for the L sample (Fig. S1a), this PL-700 material has rod-shape morphology (Fig. 1a and b) with large amount of pores. In high resolution images (Fig. 1c and d), the pores with different size can be observed clearly. The pores were closely distributed in the surface, but not connected with each other. The walls were so thin that it was damaged when irradiated by TEM beam (Fig S2a and b). Meanwhile, pores were also observed in samples PL-600 (Fig. S3a), PL800 (Fig. S5a), and PL-900 (Fig. S6a). Different from PL-700, the pores in the other samples were obviously aggregated. This difference in the morphology of the activated carbon samples was primarily due to the activation temperature. Aniline monomer can be easily polymerized, and polyaniline can grow into different shapes, such as rods or spheres, even at room temperature. At high temperatures, the activation agent $\mathrm{KOH}$ reacted with carbon, producing gases $\left(\mathrm{CO}, \mathrm{H}_{2} \mathrm{O}\right.$ and $\left.\mathrm{CO}_{2}\right)$, forming pores and leaving behind potassium salts $(\mathrm{K}, \mathrm{KOH}$ and $\mathrm{K}_{2} \mathrm{CO}_{3}$ ) [26]. The interconnected cavities in the porous carbon might serve as reservoirs for the electrolyte, Thus, the pores with different size provided channels for ion transport and the thin walls led to short transport distance, resulting in small inner pore ions transferring resistance [27]. These characteristics were expected to promote the supercapacitor performance, as will be discussed later. In addition, elemental mapping was performed and shown a homogeneous distribution of elements (C, N and O) in all activated samples (Fig. S3, S4 and S5).

$\mathrm{N}_{2}$ sorption/desorption was conducted to characterize the surface area and pores size distribution (Fig. 2a and b). The BET specific surface area were 1886, 2265, 2467, and $2014 \mathrm{~m}^{2} \mathrm{~g}^{-1}$ for samples PL-600, PL-700, PL-800 and PL-900, respectively, and showed dependence on the activation temperature. Interestingly, the pore size distribution (Fig. 2 b) for all the samples 
137 showed similar pore width centered at $27 \mathrm{~nm}$. The similar pore structure was probably resulted 138 from using the equal amount of $\mathrm{KOH}$ and biomass for all samples activation. The samples 139 possessed higher BET specific surface area with proper pore sizes are expected to be a promising

EDLC electrode material. Raman spectra of the samples are shown in Fig. 2c. Two apparent peaks in the spectra were found, corresponding to the $D$ band at $1346 \mathrm{~cm}^{-1}$ and $G$ band at 1585 $\mathrm{cm}^{-1}$. The $G$ band revealed the formation of graphitic carbon. The $D$ band reflected the degree of disorder which was associated with defects in hexagonal graphitic layers. The relative intensity ratio of $D$ and $\mathrm{G}$ bands $\left(I_{D} / I_{G}\right)$ was also used to evaluate degree of crystallinity, the smaller value means the higher degree of graphitization and less disordered nature of carbon $[28,29]$. The $I_{D} / I_{G}$ values were estimated to be $1.33,1.10,1.07$ and 1.04 for the samples activated at $600{ }^{\circ} \mathrm{C}, 700{ }^{\circ} \mathrm{C}$, $800{ }^{\circ} \mathrm{C}$ and $900{ }^{\circ} \mathrm{C}$, respectively. The values decreased as the temperature increased, indicating the degree of graphitization was enhanced and electrical conductivity would be promoted.

To clarify the surface chemical compositions of the obtained samples, XPS measurement was employed. As expected, C $(285 \mathrm{eV}), \mathrm{O}(532 \mathrm{eV})$ signals were detected, however, no $\mathrm{N}$ signal was detected in the XPS survey spectra for all four samples (Fig. 2d). This result appeared inconsistent with the results of element mapping in TEM and given the $\mathrm{N}$-containing raw material we used. Elemental analysis was subsequently carried out to analyze the compositions of the samples. As presented in Table 1, $\mathrm{N}$ was indeed detected along with $\mathrm{C}$ and $\mathrm{O}$ in all four samples. The content of $\mathrm{N}$ was found to be $0.64 w t \%, 0.29 w t \%, 0.26 w t \%$ and $0.33 w t \%$ for PL600, PL-700, PL-800, and PL-900, respectively. Considering the XPS result, it was likely that N was accumulated below the surface because this surface analysis technique had a detection depth only ca. $10 \mathrm{~nm}$. Introducing nitrogen into activated carbon has proven to be effective in improving the materials conductivity and subsequently promoting the capacitance performance 
60 [30]. Therefore, it is important to confirm the existence of nitrogen. The presence of $\mathrm{N}$ was 161 expected to induce additional pseudo-capacitance via reversible redox reactions and improve the 162 wettability between the electrodes and electrolytes [21].

163 To evaluate the specific capacitance in the two-electrode system, the following equation [31] was 164 used:

where $C\left(\mathrm{~F} \mathrm{~g}^{-1}\right)$ is the specific capacitance, $I(\mathrm{~A})$ is the discharge current, $\Delta t(\mathrm{~s})$ is the discharge time, $\Delta v(\mathrm{~V})$ is the voltage change (excluding the $i R$ drop) within the discharge time, and $M(\mathrm{~g})$ is the total mass of the active materials on the two electrodes, factor 4 is to adjust the capacitance of the cell and the combined mass of two electrodes to the capacitance and mass of a single electrode [32].

Fig. 3a showed the CV curves of PL-600, PL-700, PL-800, and PL-900 at a scanning rate of 20 $\mathrm{mV} \mathrm{s}^{-1}$. The $\mathrm{CV}$ curves tended to be regular rectangle with the increase in the activation temperature, indicating materials have promising potential as EDLC electrodes. The sample PL700 exhibited the largest specific capacitance of $333 \mathrm{~F} \mathrm{~g}^{-1}$, which was significantly larger than that of 21 (Fig. S1b), 269, 247, $179 \mathrm{~F} \mathrm{~g}^{-1}$ for L, PL-600, PL-800 and PL-900, respectively. In addition, PL-700 behaved better than PL-600, PL-800 and PL-900 at different scanning rates (5, 10, 20, 50, 100 and $200 \mathrm{mV} \mathrm{s}^{-1}$ ), as shown in Fig. S7. Although PL-700 exhibited the highest specific capacitance among these four samples, it was not the sample with the largest specific surface area or $\mathrm{N}$ content. This seems not in consistent with the expected contribution from $\mathrm{N}$ and porous structure. The most possible reason was that the PL-700 sample had larger effective specific surface area that provided better accessibility to the electrolyte and facilitated efficient 
182 ion transport with lower resistance [33]. In addition, it is well known that introducing $\mathrm{N}$ enhances the electrical conductivity of carbon and produces pseudocapacitance effect to improve the specific capacitance. Furthermore, among the four types of N-groups (pyridinic N, pyrrolic N, quaternary $\mathrm{N}$, and pyridinic $\mathrm{N}$-oxide) formed after carbonization [34], only pyridinic $\mathrm{N}$ and pyrrolic $\mathrm{N}$ contributed to enhancing specific capacitance [35]. Although $\mathrm{N}$ was not detected by XPS in our samples due to the special structure of the samples mentioned above, it was still quite likely that PL-700 possessed more pyridinic $\mathrm{N}$ and pyrrolic $\mathrm{N}$ than the other samples.

189 The galvanostatic charge/discharge curves of activated electrodes at current density of $1.0 \mathrm{~A} \mathrm{~g}^{-1}$ 190 was shown in Fig. 3b. As other samples, PL-700 also displayed a symmetric triangle curve and 191 no obvious Ohmic drop $\left(I R_{d r o p}\right)$ was observed, which was an indicative of good capacitive 192 performance [36].

193 Impedance was considered as an important index to access the electrode materials for EDLC. 194 The EIS measurement was performed in the range from 0.1 to $100 \mathrm{kHz}$ in the two-electrode cell 195 to characterize the resistance (as shown in Fig. 3c). At the low frequency region, a straight line 196 could be observed, which represented the contact resistance. The steeper line indicates better 197 behavior of the electrodes [35]. In the high frequency region, all the samples exhibited an 198 obvious semicircle for which the smaller radius means the lower ESR (inset in Fig. 3c). This 199 behavior indicates equivalent series resistance (ESR) referring to electrode conductivity and the 200 charge-transfer resistance in the electrode materials. The PL-700 exhibited the steepest straight 201 line and smallest radius at low and high frequencies, demonstrating the excellent electrochemical 202 characteristics.

203 The cyclic stability of the electrodes was measured by charge/discharge at a constant current 204 density of $1.0 \mathrm{~A} \mathrm{~g}^{-1}$, as shown in Fig. 3d. After 1, 000 charge/discharge cycles, all the samples 


\section{Conclusion}

The rod-shape porous carbon derived from aniline modified lignin has been successfully prepared via $\mathrm{KOH}$ activation. The activation temperature determines the microstructure and morphology of the resulting carbon. The materials activated at $700{ }^{\circ} \mathrm{C}$ exhibited high specific surface area with inconnected cavities, which lead to the highest specific capacitance of $336 \mathrm{~F} \mathrm{~g}^{-1}$, smallest resistance of $0.9 \Omega$ and excellent stability in electrochemical performance as compared to the materials activated at different temperatures $\left(600,800\right.$, and $\left.900{ }^{\circ} \mathrm{C}\right)$. The PL-700 also 
2

3

4226 exhibited remarkable operational characteristics in terms of power and energy density. The 8

superior performance of PL-700 indicates that it is a promising electrode material for EDLC.

\section{Acknowledgement}

229 This research was funded by the following projects: 1) "Development of high value carbon based 230 adsorbents from thermochemically produced biochar" 2011-67009-20030 USDA-NIFA 231 Agriculture and Food Research Initiative Sustainable Bioenergy Program; 2) NSF EPSCoR 232 Track II Dakota BioCon center supported Mr. Wang Keliang for his PhD study; 3) The 233 Characterization Facility, University of Minnesota, which receives partial support from NSF 234 through the MRSEC program; 4) NSF award \#1462389; 5) NSF CHE-0840507; and NSF award $235 \quad \# 1536209$. 
2

3

248

249

250

251

252 References

253 [1] M. Zhi, C. Xiang, J. Li, M. Li, N. Wu, Nanoscale 5 (2013) 72-88.

254 [2] S. Faraji, F.N. Ani, Renew Sust. Energ. Rev. 42 (2015) 823-834.

255 [3] N. Devillers, S. Jemei, M.-C. Péra, D. Bienaimé, F. Gustin, J. Power Sources 246 (2014) 596256608.

257 [4] S. Faraji, F.N. Ani, J. Power Sources 263 (2014) 338-360.

258 [5] J. Yan, Z. Fan, W. Sun, G. Ning, T. Wei, Q. Zhang, R. Zhang, L. Zhi, F. Wei, Adv. Fun. 259 Mater. 22 (2012) 2632-2641.

260 [6] Y. He, W. Chen, X. Li, Z. Zhang, J. Fu, C. Zhao, E. Xie, ACS Nano 7 (2012) 174-182.

261 [7] X.-h. Xia, J.-p. Tu, Y.-q. Zhang, Y.-j. Mai, X.-l. Wang, C.-d. Gu, X.-b. Zhao, Rsc Adv. 2 262 (2012) 1835-1841.

263 [8] S. Vijayakumar, S. Nagamuthu, G. Muralidharan, ACS Appl. Mater. Inter. 5 (2013) 21882642196.

265 [9] H. Jiang, J. Ma, C. Li, Chem. Comm. 48 (2012) 4465-4467.

266 [10] B.P. Bastakoti, Y. Kamachi, H.S. Huang, L.C. Chen, K.C.W. Wu, Y. Yamauchi, Eur. J. 267 Inorg. Chem. 2013 (2013) 39-43.

268 [11] C. Largeot, C. Portet, J. Chmiola, P.-L. Taberna, Y. Gogotsi, P. Simon, J. Am. Chem. Soc. 269130 (2008) 2730-2731.

270 [12] M. Chen, X. Kang, T. Wumaier, J. Dou, B. Gao, Y. Han, G. Xu, Z. Liu, L. Zhang, J. Solid 58 
4272 [13] Y. Huang, J. Liang, Y. Chen, Small 8 (2012) 1805-1834.

$276 \quad 880-889$.

277 [17] M. Zhi, F. Yang, F. Meng, M. Li, A. Manivannan, N. Wu, ACS Sust. Chem. \& Eng. 2 (2014) $278 \quad 1592-1598$.

279 [18] D. Jiménez-Cordero, F. Heras, M.A. Gilarranz, E. Raymundo-Piñero, Carbon 71 (2014) $280 \quad 127-138$

281 [19] Y.S. Yun, M.H. Park, S.J. Hong, M.E. Lee, Y.W. Park, H.-J. Jin, ACS Appl Mater. \& Inter. $2827(2015) 3684-3690$.

283 [20] X. He, P. Ling, M. Yu, X. Wang, X. Zhang, M. Zheng, Electrochim. Acta 105 (2013) 635284641.

285 [21] W. Si, J. Zhou, S. Zhang, S. Li, W. Xing, S. Zhuo, Electrochim. Acta 107 (2013) 397-405.

286 [22] Z. Cai, L. Li, J. Ren, L. Qiu, H. Lin, H. Peng, J. Mater.Chem A 1 (2013) 258-261.

287 [23] R.C.Y. King, F. Roussel, J.-F. Brun, C. Gors, Synthetic Met. 162 (2012) 1348-1356.

288 [24] J. Han, G. Xu, B. Ding, J. Pan, H. Dou, D.R. MacFarlane, J. Mater. Chem. A 2 (2014) 53522895357.

290 [25] S. Brunauer, P.H. Emmett, E. Teller, J. Am. Chem. Soc. 60 (1938) 309-319.

291 [26] J. Wang, S. Kaskel, J. Mater. Chem. 22 (2012) 23710-23725.

292 [27] C. Ruan, K. Ai, L. Lu, RSC Adv. 4 (2014) 30887-30895.

293 [28] S. Shanmugam, T. Osaka, Chem. Comm. 47 (2011) 4463-4465. 
2

3

[29] L.-F. Chen, Z.-H. Huang, H.-W. Liang, W.-T. Yao, Z.-Y. Yu, S.-H. Yu, Energ. \& Environ. 295 Sci. $6(2013)$ 3331-3338.

296 [30] B. Zheng, J. Wang, F.-B. Wang, X.-H. Xia, Electrochem. Comm. 28 (2013) 24-26.

297 [31] Y. Tan, C. Xu, G. Chen, Z. Liu, M. Ma, Q. Xie, N. Zheng, S. Yao, ACS Appl Mater. \& 298 Inter. 5 (2013) 2241-2248.

299 [32] M.D. Stoller, R.S. Ruoff, Energ. \& Environ. Sci. 3 (2010) 1294-1301.

300 [33] L. Zhang, F. Zhang, X. Yang, G. Long, Y. Wu, T. Zhang, K. Leng, Y. Huang, Y. Ma, A. Yu, 301 Sci. Rep. 3 (2013) 1408-1416.

302 [34] T. Zhu, J. Zhou, Z. Li, S. Li, W. Si, S. Zhuo, J. Mater. Chem. A 2 (2014) 12545-12551.

303 [35] X. Hong, K. Hui, Z. Zeng, K. Hui, L. Zhang, M. Mo, M. Li, Electrochim. Acta 130 (2014) $304 \quad 464-469$.

305 [36] Q. Wu, Y. Xu, Z. Yao, A. Liu, G. Shi, ACS Nano 4 (2010) 1963-1970.

306 [37] J. Yan, J. Liu, Z. Fan, T. Wei, L. Zhang, Carbon 50 (2012) 2179-2188. 
318 Table 1 Elemental analysis of PL-600, PL-700, PL-800 and PL-900.

\begin{tabular}{ccccc}
\hline Sample & Carbon $(w t \%)$ & Hydrogen $(w t \%)$ & Nitrogen $(w t \%)$ & Oxygen $(w t \%)$ \\
\hline PL-600 & 74.52 & 2.91 & 0.64 & 21.93 \\
PL-700 & 87.28 & 1.19 & 0.29 & 11.24 \\
PL-800 & 91.88 & 1.21 & 0.26 & 6.65 \\
PL-900 & 91.70 & 0.60 & 0.33 & 7.37 \\
\hline
\end{tabular}


Figure(s)

Click here to download Figure(s): Figures.docx

Fig. 1

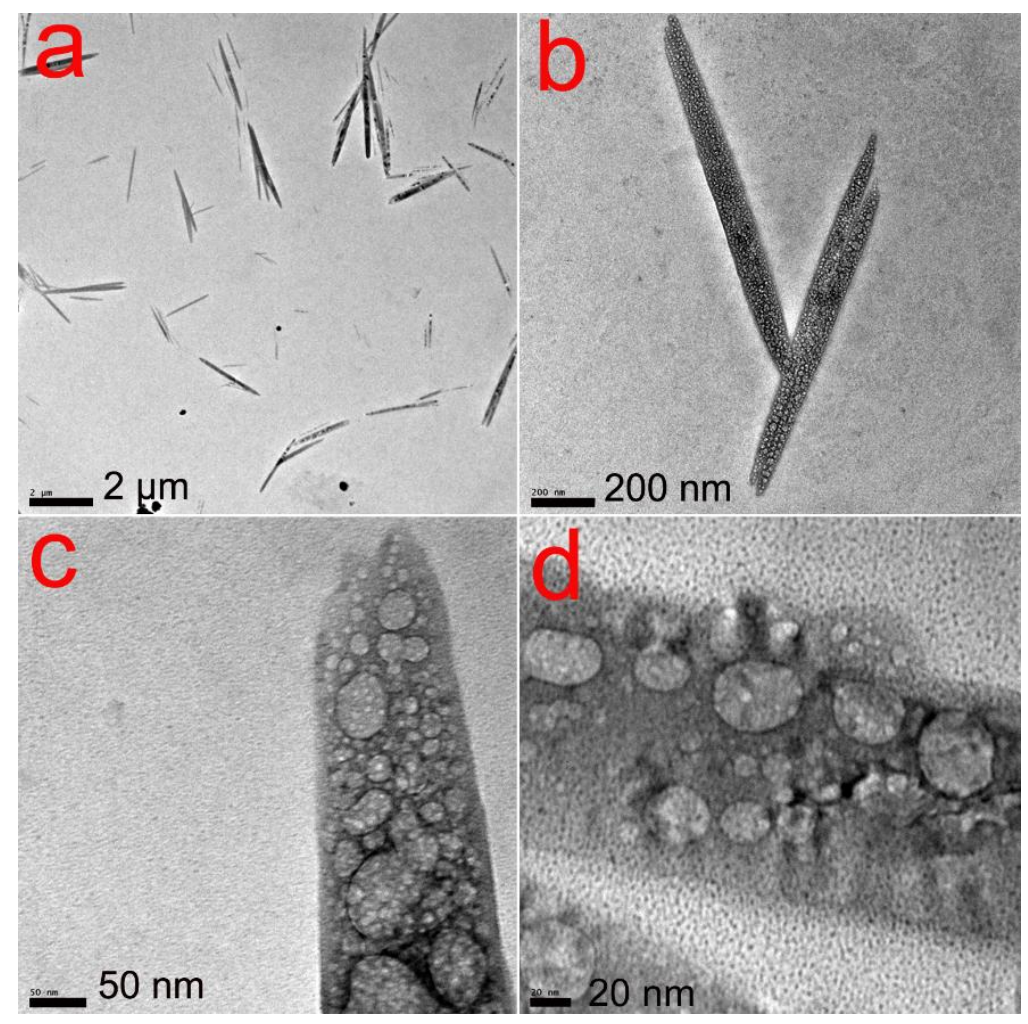


Fig. 2
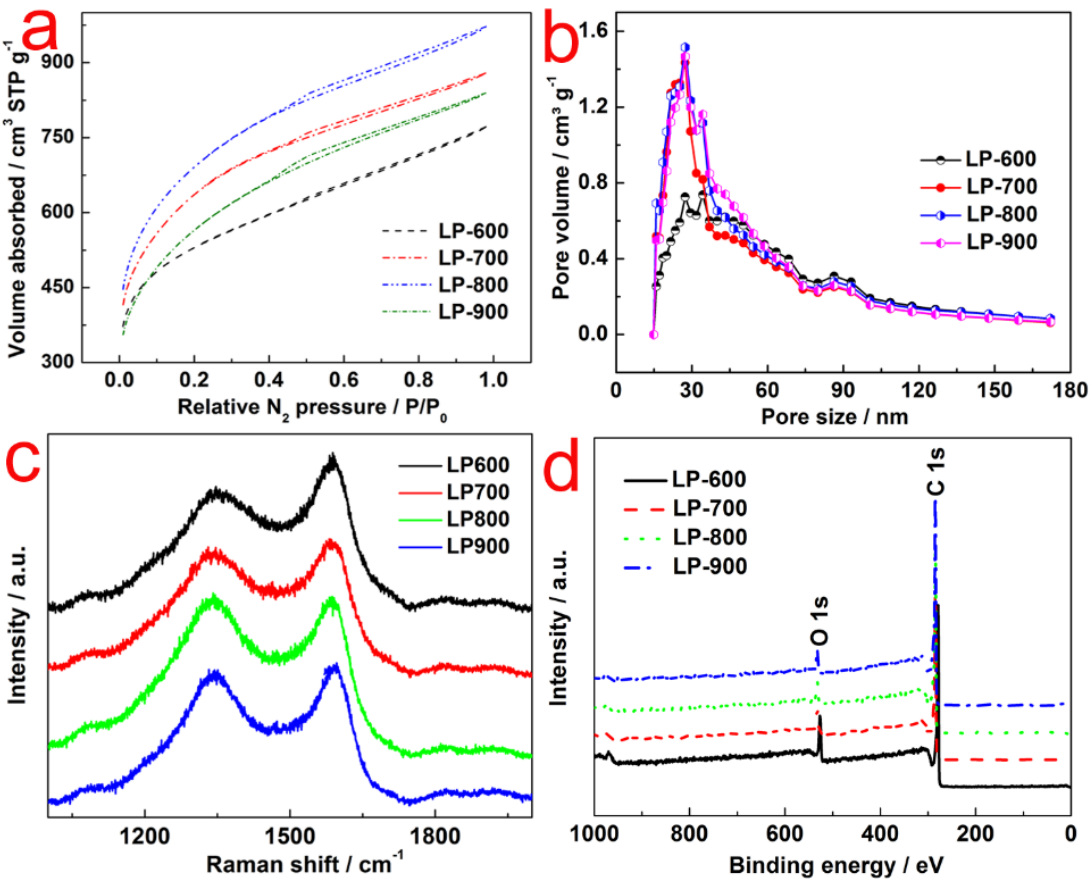
Fig. 3
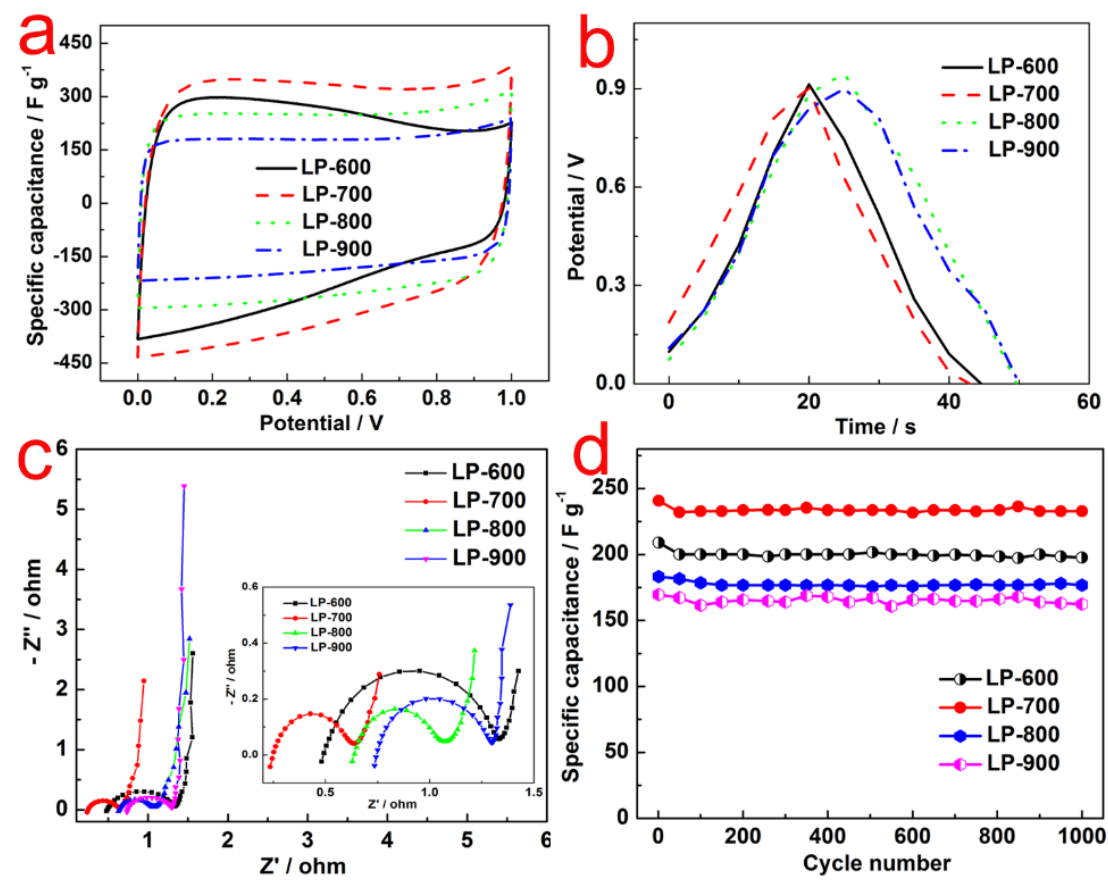
Fig. 4

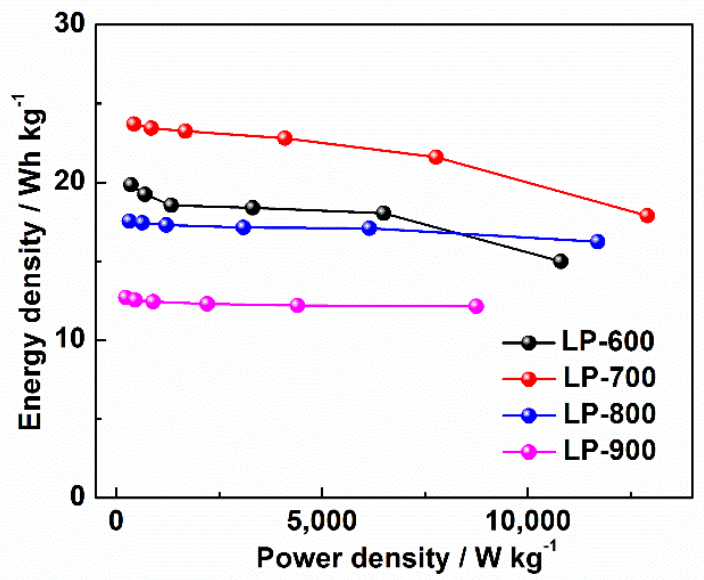


Fig. 1 Different magnifications TEM images of PL-700.

Fig. $2 \mathrm{~N}_{2}$ sorption-desorption isotherms (a) and pore size distribution (b), Raman spectra (c) and XPS survey spectra (d) of PL-600, PL-700, PL-800, and PL-900.

Fig. $3 \mathrm{CV}$ curves (a) at scanning rate $20 \mathrm{mV} \mathrm{s}^{-1}$, galvanostatic charge/discharge (b) nyquist plots (c) and cycle life (d) at current density $1.0 \mathrm{~A} \mathrm{~g} \mathrm{~g}^{-1}$ of PL-600, PL-700, PL-800 and PL-900 electrodes in $6 \mathrm{~mol} \mathrm{~L}^{-1} \mathrm{KOH}$ electrolyte.

Fig. 4 Ragone plots related to energy and power densities of PL-600, PL-700, PL-800 and PL900 electrodes. 